\title{
Induction of maturation and activation of human dendritic cells: $A$ mechanism underlying the beneficial effect of Viscum album as complimentary therapy in cancer
}

\author{
Sri Ramulu Elluru1,2,3,4, Jean-Paul Duong van Huyen 1,2,3,5, \\ Sandrine Delignat ${ }^{1,2,3}$, Michel D Kazatchkine ${ }^{1,2,3}$, Alain Friboulet ${ }^{4}$, \\ Srini V Kaveri*1,2,3 and Jagadeesh Bayry ${ }^{1,2,3}$
}

Address: ${ }^{1}$ Centre de Recherche des Cordeliers, Université Pierre et Marie Curie - Paris6, UMR S 872, Paris, 75006, France, ${ }^{2}$ Université Paris Descartes, UMR S 872, Paris, F-75006, France, ${ }^{3}$ INSERM, U872, Paris, F-75006, France, ${ }^{4}$ CNRS UMR6022, Université de Technologie, Compiègne, France and ${ }^{5}$ Laboratoire d'Anatomie Pathologique, Hôpital Européen Georges Pompidou, 20-40 rue Leblanc, Paris, France

Email: Sri Ramulu Elluru - sri-ramulu.elluru@crc.jussieu.fr; Jean-Paul Duong van Huyen - jp.dvh@wanadoo.fr; Sandrine Delignat - sandrine.delignat@crc.jussieu.fr; Michel D Kazatchkine - michel.kazatchkine@crc.jussieu.fr;

Alain Friboulet - alain.friboulet@utc.fr; Srini V Kaveri* - srini.kaveri@crc.jussieu.fr; Jagadeesh Bayry - jagadeesh.bayry@crc.jussieu.fr

* Corresponding author

Published: 4 June 2008

BMC Cancer 2008, 8:161 doi:|0.1186/|47|-2407-8-16|
Received: 17 July 2007

Accepted: 4 June 2008

This article is available from: http://www.biomedcentral.com/l47I-2407/8//6I

(c) 2008 Elluru et al; licensee BioMed Central Ltd.

This is an Open Access article distributed under the terms of the Creative Commons Attribution License (http://creativecommons.org/licenses/by/2.0), which permits unrestricted use, distribution, and reproduction in any medium, provided the original work is properly cited.

\begin{abstract}
Background: Viscum album (VA) preparations have been used as a complimentary therapy in cancer. In addition to their cytotoxic properties, they have also been shown to have immunostimulatory properties. In the present study, we examine the hypothesis that the VA preparations induce activation of human DC that facilitates effective tumor regression.

Methods: Four day old monocyte-derived immature DCs were treated with VA Qu Spez at 5, 10 and $15 \mu \mathrm{g} / \mathrm{ml}$ for $48 \mathrm{hrs}$. The expression of surface molecules was analyzed by flow cytometry. The ability of Qu Spez-educated DC to stimulate $T$ cells was analyzed by allogeneic mixed lymphocyte reaction and activation of Melan-A/MART-I-specific M77-80 CD8+T cells. Cytokines in cell free culture supernatant was analyzed by cytokine bead array assay.

Results: VA Qu Spez stimulated DCs presented with increased expression of antigen presenting molecule HLA-DR and of co-stimulatory molecules CD40, CD80 and CD86. The VA Qu Spez also induced the secretion of inflammatory cytokines IL-6 and IL-8. Further, Qu Spez-educated DC stimulated CD4+T cells in a allogeneic mixed lymphocyte reaction and activated melanoma antigen Melan-A/MART-I-specific M77-80 CD8+T cells as evidenced by increased secretion of TNF- $\alpha$ and IFN $\gamma$.

Conclusion: The VA preparations stimulate the maturation and activation of human DCs, which may facilitate anti-tumoral immune responses. These results should assist in understanding the immunostimulatory properties of VA preparations and improving the therapeutic strategies.
\end{abstract}




\section{Background}

VA preparations are aqueous extracts from Viscum album (also known as European mistletoe) consisting of different types of lectins [1-3]. In addition to mistletoe lectins (ML), biologically active components of VA preparations include viscotoxins, several enzymes, peptides (such as viscumamide), amino acids, thiols, amines, polysaccharides, cyclitoles, lipids, phytosterols, triterpines, flavonoids, phenylpropanes and minerals $[3,4]$. VA preparations have been used as a complimentary therapy in cancer. Several studies have reported the clinical benefits of VA preparations in cancer patients $[5,6]$. Treatment with VA preparations or purified ML has also been shown to be associated with tumor regression in several experimental models $[7,8]$. The mechanisms underlying the anti-tumoral activity of VA preparations are complex and not completely understood. The proposed mechanisms include induction of apoptosis of tumor cells and lymphocytes, inhibition of angiogenesis and stimulation of the cellular compartment of the immune system [9-14].

During the course of tumor development, the tumor evades the immune system through the secretion of various factors such as VEGF, IL-10 and $\mathrm{PGE}_{2}$ that have been shown to inactivate the immune system [15]. The different pathways of immune evasion by tumors involve: induction of immune tolerance, resistance to killing by immune effector cells, and imparting functional paralysis of professional antigen presenting cells (APCs) such as dendritic cells (DCs) [15].

DCs are the professional APCs that are specialized in the uptake of antigens and their transport from peripheral tissues to the lymphoid organs $[16,17]$. Because of their capacity to stimulate naive T cells, DCs have a central role in the initiation of primary immune responses [18]. DCs reside in periphery as immature cells with a high ability to endocytose target antigens [19]. Upon receiving appropriate stimuli and in the context of inflammation, DCs undergo maturation process characterized by increased surface expression of antigen presenting HLA molecules and co-stimulatory molecules such as CD80 and CD86 and secrete several pro-inflammatory cytokines [20].

Tumor cells suppress the maturation and activation process of DCs [21]. Thus, several studies have demonstrated that DCs that reside in the tumor site or in the vicinity of tumor are immature with a decreased ability to stimulate $\mathrm{T}$ cells $[22,23]$. In addition, tumor cells secrete several anti-inflammatory cytokines such as IL-10 and TGF, which can suppress the functions of DCs [24-26]. In view of the anti-tumoral and immunostimulatory properties of VA preparations, and the central role of DCs in antitumoral immune response, we examined the hypothesis that VA preparations stimulate the DCs, which in part explains the mechanisms underlying the beneficial effect of VA preparations in cancer therapy.

\section{Methods}

\section{Antibodies and reagents}

Recombinant human (rh) interleukin-4 (IL-4) was obtained from R\&D Systems (Lille, France), and rh granulocyte macrophage-colony-stimulating factor (rh GMCSF), rhIL-2 and rhTNF $\alpha$ were obtained from Immunotools (Friesoythe, Germany). FITC-conjugated monoclonal antibodies (mAb) to HLA-DR and CD80, PE-conjugated mAbs to CD86, CD40 and CD83 and APC-conjugated mAbs to $\mathrm{CD} 11 \mathrm{c}$ were obtained from BD biosciences (France).

\section{VA preparations}

VA Qu Spez, was a kind gift from Weleda AG (Arlesheim, Switzerland). VA Qu Spez is the extract of Viscum album growing on oak trees. The VA preparations are therapeutic preparations that are free from endotoxins. VA preparations are formulated in sodium chloride $(\mathrm{NaCl} 0.9 \%)$ isotonic solution as $5 \mathrm{mg} / \mathrm{ml}$ vials. During the manufacturing process, VA preparations are prepared by standardizing the levels of Mistletoe lectins and Viscotoxins. The concentrations of the lectins and viscotoxins of the different preparations used in the study are summarized in Table 1.

\section{Generation and culture of monocyte-derived human dendritic cells}

Peripheral blood mononuclear cells (PBMC) were isolated from buffy coats of healthy donors purchased from Hopital Hotel Dieu, Etablissement Français du Sang (06/ EFS/029, dated 29.05.2006), upon ethical approval for the use of such materials. The percentage of monocytes in the PBMC preparations was in the range of 9 to $14 \%$. Monocytes were positively isolated using CD14 beads (Miltenyi Biotec, France). The purity of the monocytes after purification is $>98 \%$. Immature DCs were generated by culturing monocytes for 4 days in RPMI 1640 contain-

Table I: Concentrations of Mistletoe Lectins and Viscotoxins in VA Qu Spez

\begin{tabular}{lccc}
\hline Preparation & Concentration used $(\mu \mathrm{g} / \mathbf{m l})$ & Lectin $(\mathbf{n g} / \mathbf{m l})$ & Viscotoxin $(\mathbf{n g} / \mathbf{m l})$ \\
\hline VA Qu Spez & 5 & 0.375 & 0.012 \\
VA Qu Spez & 10 & 0.750 & 0.024 \\
VA Qu Spez & 15 & 1.125 & 0.036 \\
\hline
\end{tabular}


ing 10\% FCS, $50 \mathrm{U} / \mathrm{ml}$ penicillin, $50 \mu \mathrm{g} / \mathrm{ml}$ streptomycin, rhIL-4 (500 IU/106 cells), and rhGM-CSF (1000 IU/10 cells). Half of the medium, including all supplements, was replaced on second day.

\section{Analysis of the expression of surface molecules by flow cytometry}

To investigate the effect of VA Qu Spez on DCs, $0.5 \times 10^{6}$ immature four-day old DCs were either untreated or treated with TNF $\alpha$ (15 ng) or VA preparations $(5,10$ and $15 \mu \mathrm{g}$ ) for $48 \mathrm{~h}$. On day 6 , cell surface staining was performed with specifically labeled mAbs and proceeded for flow-cytometry (LSR II, BD Biosciences, France). Ten thousand events were recorded and analyzed for each sample. Data were analyzed by BD FACSDIVA software (BD Biosciences, France).

\section{Mixed lymphocyte reaction (MLR) with allogenic CD4+ T cells}

Responder CD4+ T cells used for allogeneic MLR assays were isolated from PBMC of healthy donors using a negative isolation kit (Dynal biotech-Invitrogen, France). DCs following $48 \mathrm{hr}$ treatment with VA Qu Spez were washed extensively and were seeded with $1 \times 10^{5}$ responder allogeneic T cells at DC:T cell ratios of 1:10, 1:20 and 1:40. After 4 days, the cells were pulsed for $16 \mathrm{~h}$ with $0.5 \mu \mathrm{Ci}$ $(0.037 \mathrm{MBq})$ of $\left({ }^{3} \mathrm{H}\right)$ thymidine. Radioactive incorporation was measured by standard liquid scintillation counting. The proliferation of cells was measured as counts per minute (mean \pm SEM of triplicate values) after subtracting values of responder $\mathrm{T}$ cell cultures alone.

\section{Anergy assay to determine the activation status of the CD4 $T$ cells in the co-culture with VA-treated DCs}

The anergy assay was performed according to a modified protocol originally described by Steinbrink et al [27]. Briefly, four-day old DCs were treated for 48 hrs with VA Qu Spez $(15 \mu \mathrm{g} / \mathrm{ml})$ or untreated or TNF $\alpha(15 \mathrm{ng} / \mathrm{ml})$. Responder CD4+ T cells were then co-cultured during the first incubation at a density of $10^{5}$ cells with $10^{4} \mathrm{DC}$ for 72 hrs. Then, $\mathrm{T}$ cells from the co-cultures were isolated by using CD4+ beads (Miltenyl Biotech) and rested for $24 \mathrm{hrs}$ in the culture medium containing $2 \mathrm{U} / \mathrm{ml}$ IL-2. Subsequently, CD4+ T cells were re-stimulated with DCs generated from the same donor as that used for the first stimulation and have undergone similar VA Qu Spez treatment. After $48 \mathrm{hrs}$, the cells were pulsed for $16 \mathrm{~h}$ with $0.5 \mu \mathrm{Ci}(0.037 \mathrm{MBq})$ of $\left({ }^{3} \mathrm{H}\right)$ thymidine. Radioactive incorporation was measured by standard liquid scintillation counting. The proliferation of cells was measured as counts per minute (mean \pm SEM of triplicate values). Tests were conducted in triplicates. Additionally, the levels of cytokines TNF- $\alpha$ and IFN $\gamma$ in the co-culture were analysed.

\section{Activation of melanoma specific cytotoxic $T$ cell (CTL) clones by VA Qu Spez-treated DCs}

The melan-A-specific CTL clone M77-80 that was derived from tumor infiltrating lymphocytes of melanoma patient M77 is a kind gift from Dr. Nathalie Labarriere and Dr. Francine Jotereau [28,29]. The VA Qu Spez-treated DCs from HLA matched donor (HLA-A2, 104/well/200 $\mu \mathrm{l}$ RPMI 1640 medium supplemented with 10\% AB serum) were cultured overnight with M77 CTLs $\left(10^{5}\right)$ in 96 well round-bottomed plates along with the MART- 1 peptide ( 1 $\mu \mathrm{M})$ and $25 \mathrm{IU} / \mathrm{mL}$ rh IL-2. The activation of M77-80 was analyzed by measuring IFN $\gamma$ and TNF $\alpha$ in the cell freesupernatants.

\section{Analysis of cytokines}

Cytokines in the cell-free culture supernatant were quantified using BD CBA Human Inflammation kit and Human Th1/Th2 kits (BD Biosciences, France).

\section{Statistical analysis}

Statistical significance was determined using the MannWhitney U test.

\section{Results}

VA Qu Spez enhances the expression of antigen presenting and co-stimulatory molecules on human DCs

We initially characterized the effect of VA Qu Spez on the phenotype of human DCs. Four-day old immature DCs were treated with VA preparations for $48 \mathrm{hrs}$ and cells were analyzed for the expression of various surface molecules (Figure 1). We have used DCs treated with $15 \mathrm{ng} / \mathrm{ml}$ of TNF- $\alpha$ as control in addition to the DCs that were left untreated. VA Qu Spez enhanced the expression by DCs of co-stimulatory molecules CD80 and CD86 (Figure 1) in dose-dependent manner. The expression of CD80 on DCs by $15 \mu \mathrm{g} / \mathrm{ml}$ concentration of VA Qu Spez $(81.74 \pm 2.3 \%$ population and $1632.8 \pm 152$ mean fluorescence intensity, MFI) was comparable to the DCs treated with TNF- $\alpha$ $(84.93 \pm 1.1 \%$ and $1644.25 \pm 195.4 \mathrm{MFI})$. In addition, Qu Spez also significantly enhanced the percentage expression CD86 in a dose-dependent manner (Figure 1). However, the expression of HLA-DR, CD40 and CD83 were either unaltered or marginally increased (data not shown).

\section{VA Qu Spez induces the secretion of pro-inflammatory cytokines IL-6 and IL-8 by DCs}

In addition to co-stimulatory molecules, DC-derived cytokines play a crucial role in priming T-cell response. We therefore analyzed whether the maturation process of DCs induced by VA Qu Spez is associated with the secretion of pro-inflammatory cytokines such as IL-6 and IL-8. The control DCs secreted $86.02 \pm 23.3 \mathrm{pg} / \mathrm{ml}$ of IL- 8 and $11.55 \pm 6.28 \mathrm{pg} / \mathrm{ml}$ of IL-6 $(\mathrm{n}=5$ donors $)$. However, as shown in Figure 2, VA Qu Spez significantly stimulated 


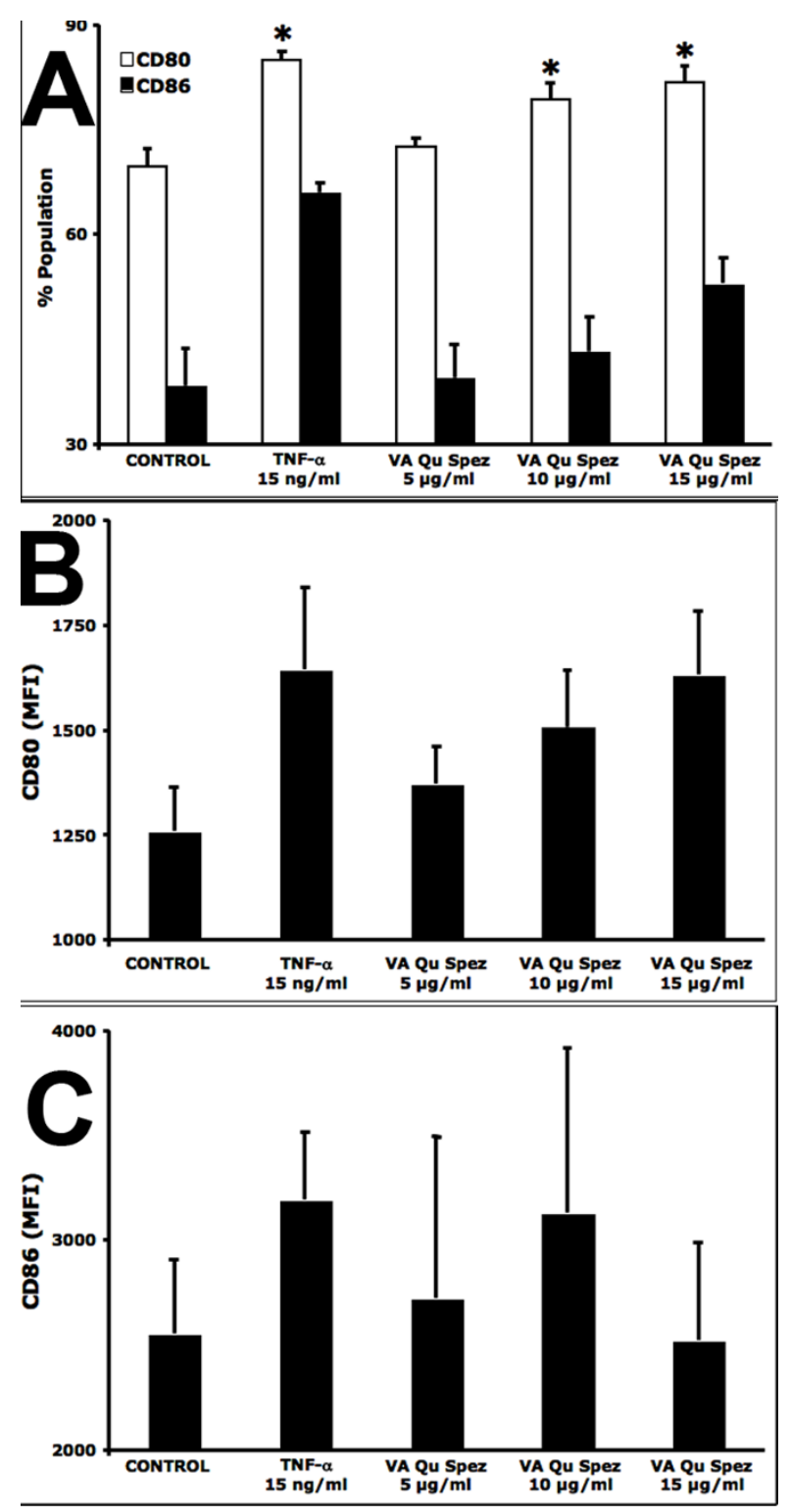

Figure I

DCs treated with VA Qu Spez show an increased expression of co-stimulatory molecules CD80 and CD86. The 4-day-old DCs $\left(0.5 \times 10^{6}\right)$ were treated with medium alone (Control) or with $15 \mathrm{ng} / \mathrm{ml}$ TNF- $\alpha$ or with 5 , 10 and $15 \mu \mathrm{g} / \mathrm{ml}$ of VA Qu Spez for 48 hours. The expression of CD80 ( $A$ and B) and CD86 ( $A$ and C) was analysed by flow cytometry (BD LSRII). Panel A shows the \% of DCs positive for CD80 (open bars) and CD86 (filled bars), while mean fluorescence intensities were presented in Panels $B$ and C. Data are presented as mean \pm SEM from from five to six independent donors. Statistical significance $(*, p<0.05)$ as analysed by Mann-Whitney test is indicated.
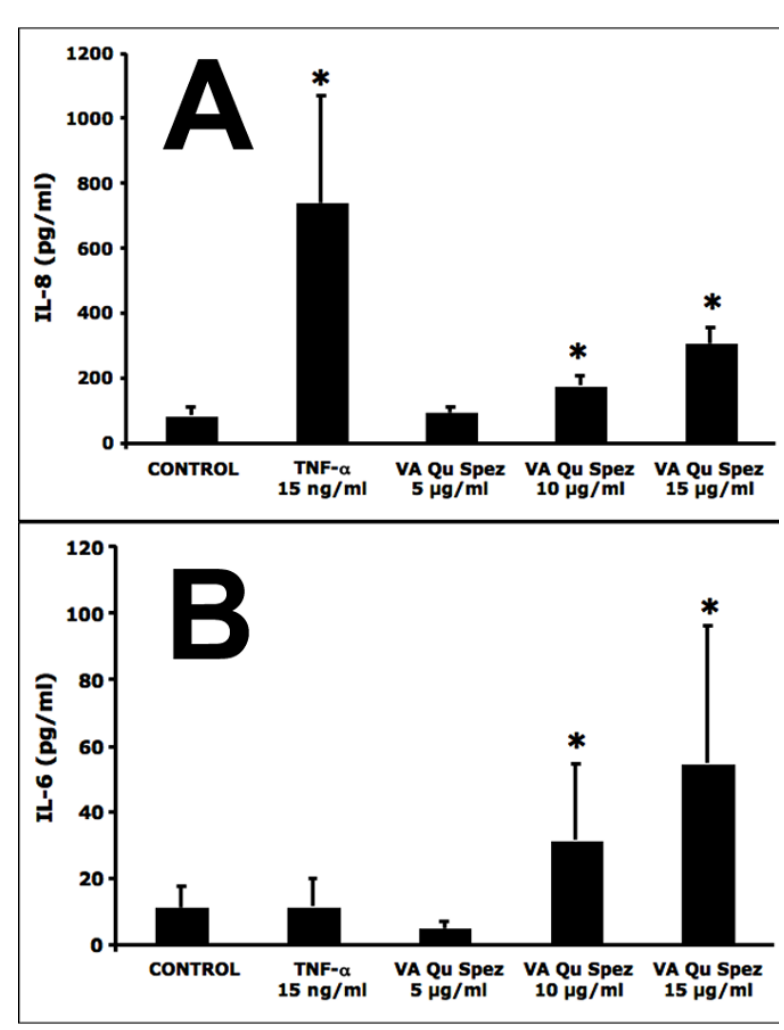

Figure 2

DCs treated with VA Qu Spez show an increased secretion of inflammatory cytokines IL-8 and IL-6. The 4-day-old DCs $\left(0.5 \times 10^{6}\right)$ were treated with medium alone (Control) or with I5 ng/ml TNF- $\alpha$ or with 5,10 and I 5 $\mu \mathrm{g} / \mathrm{ml}$ of VA Qu Spez for 48 hours. The secretion $(\mathrm{pg} / \mathrm{ml})$ of IL-8 (Panel A) and IL-6 (Panel B) in cell free supernatants were analysed by cytokine bead array assay. Data are presented as mean \pm SEM from five to six independent donors. Statistical significance $(*, p<0.05)$ as analysed by Mann-Whitney test is indicated.

the secretion of IL-8 $(308.052 \pm 48.60 \mathrm{pg} / \mathrm{ml})$ and IL-6 $(54.97 \pm 41.27 \mathrm{pg} / \mathrm{ml})$ by DCs. Together these results indicate that in addition to stimulating the expression of costimulatory molecules on DCs, VA Qu Spez induce the secretion of pro-inflammatory cytokines.

\section{VA Qu Spez-treated DCs stimulate $T$ cell proliferation}

A major function of DCs is their ability to trigger the activation and proliferation of $\mathrm{T}$ cells. We thus examined whether maturation of DCs induced by VA Qu Spez is reflected in their capacity to stimulate CD4+ T cells in an allogeneic MLR. As shown in Figure 3, VA Qu Spez-treated DCs, stimulated the proliferation of CD4 $+\mathrm{T}$ cells in a dose-dependent manner. The extent of $\mathrm{CD} 4+\mathrm{T}$ cell prolif- 


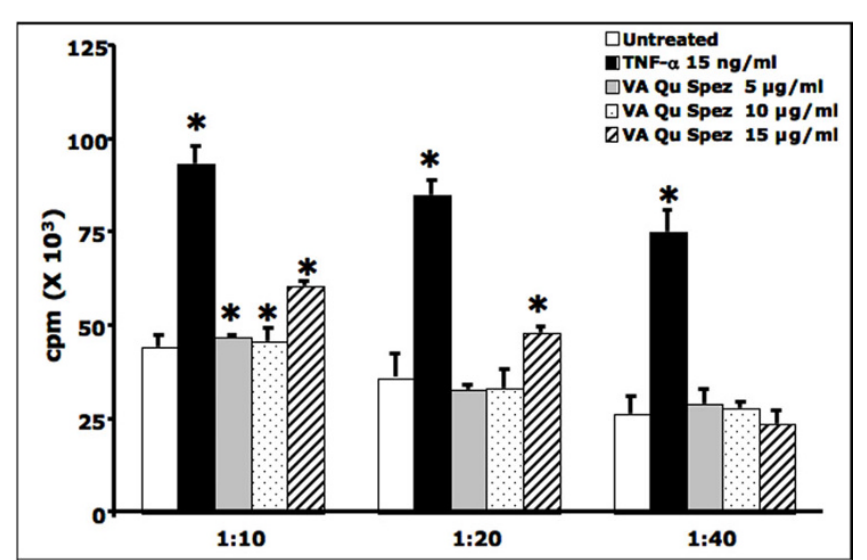

Figure 3

VA Qu Spez-treated DCs stimulate the proliferation of allogeneic CD4+ T cells. The 4-day-old DCs $(0.5 \times$ $\left.10^{6}\right)$ were treated with medium alone (Control) or with 15 $\mathrm{ng} / \mathrm{ml} \mathrm{TNF-} \alpha$ or with 5,10 and I $5 \mu \mathrm{g} / \mathrm{ml}$ of VA Qu Spez for 48 hours. After $48 \mathrm{hr}$ treatments, DCs were co-cultured with the allogeneic CD4+ T cells at different ratios in a round bottom 96-welled plate. After 4 days of co-culture, the cells were pulsed overnight with $0.5 \mu \mathrm{Ci}(0.037 \mathrm{MBq})$ of $\left({ }^{3} \mathrm{H}\right)$ thymidine to quantify T-cell proliferation. Radioactive incorporation was measured by standard liquid scintillation counting, and the results were expressed as counts per minute (mean \pm SEM of triplicate values). Statistical significance $(*, p<0.05)$ as analysed by Mann-Whitney test is indicated.

eration induced by VA Qu Spez-treated DCs was significant at DC-T cell ratios of 1:10 and 1:20.

\section{VA Qu Spez-treated DCs do not induce anergy of CD4+ T cells}

We performed anergy assay to determine the activation status of the CD4 T cells in the co-culture with VA Qu Spez-treated DCs. As shown in Figure 4a, during first cycle of CD4+ T cell stimulation in a MLR (day 0-day 7), VA Qu Spez-treated DCs $(81920 \pm 9070 \mathrm{cpm})$ show similar ability to stimulate the proliferation of CD4+ T cells as compared to TNF- $\alpha$ treated DCs $(87439 \pm 3910 \mathrm{cpm})$. Interestingly, $\mathrm{CD} 4+\mathrm{T}$ cells that were re-stimulated/challenged during second cycle of stimulation with VA Qu Spez-treated DCs show increased proliferation (202276 \pm $2052 \mathrm{cpm})$ as compared to the control DCs (76236 \pm $4436 \mathrm{cpm})$ and TNF- $\alpha$ treated DCs $(154341 \pm 3224 \mathrm{cpm})$.

To further confirm that VA Qu Spez-treated DCs do not impart CD4+T cell anergy, we analysed for the secretion of $\mathrm{T}$ cell cytokines TNF- $\alpha$ and IFN $\gamma$ in the DC-CD4+T cell cocultures. As shown in Figure 4b, CD4+ T cells that were restimulated/challenged during second cycle of stimulation with VA Qu Spez-treated DCs show increased secretion of above cytokines as compared to control DCs. These results suggest that maturation and activation of DCs induced by VA Qu Spez have functional repercussion on T cell activation and not $\mathrm{T}$ cell anergy.

\section{VA Qu Spez-treated DCs stimulate melanoma specific M77-80 CTL clone}

Since, VA preparations have been used as a complimentary therapy in cancer we examined whether VA Qu Spezstimulated DCs facilitate anti-tumoral T cell responses. Therefore, HLA-matched VA Qu Spez-treated DCs were co-cultured with Melan-A/MART-1 specific M77-80 CTL clone (Figure 5). Strikingly, VA Qu Spez-treated DCs activated tumor antigen specific CTL clone as analyzed by the secretion of cytokines TNF- $\alpha$ and IFN $\gamma$.

\section{Discussion}

Although VA preparations are widely used in clinical practice and cancer therapy, their mechanisms of action are yet to be fully understood. In our previous studies, we have shown that in addition to cytotoxic properties, VA preparations have immunostimulatory effects that facilitate tumor regression in experimental models [13]. However, to mount an effective anti-tumoral immune response, an increased expression of co-stimulatory molecules on the DCs, the sentinels of the immune system, accompanied by an enhanced secretion of pro-inflammatory cytokines that culminates in $\mathrm{T}$ cell proliferation is necessary.

DCs found within the tumor microenvironment are found to have a relatively immature phenotype characterized by low levels CD86, and surface HLA-DR expression and inability to produce pro-inflammatory cytokine [30,31]. Clinical studies with mistletoe lectins have shown that VA preparations stimulate the cytokine secretion and function of monocytes, the precursors of DCs [32]. The previous studies by Stein et al demonstrated that mistletoe extract and their isolated components influences the maturation of DC with an increased expression of co-stimulatory and antigen presenting molecules $[33,34]$. Furthermore, we found that the up-regulation of these molecules is accompanied by the induction of inflammatory cytokines by the VA preparations and stimulation of tumor specific $T$ cells. Together these results suggest that induction of maturation and activation of human DCs is one of the mechanisms underlying the beneficial effect of VA preparations as complimentary therapy in cancer.

Previously, it has been demonstrated that VA lectin induces the gene expression of IL-1 alpha, IL-1 beta, IL-6, TNF- $\alpha$, IFN- $\gamma$ and GM-CSF from PBMC [35]. A recent clinical study has shown that the CD14+ monocytes from multiple myeloma patients could be induced to differentiate into functional DCs by culturing them with the cytokine cocktail consisting of GM-CSF, IL-4, IL-6, TNF- $\alpha$ 


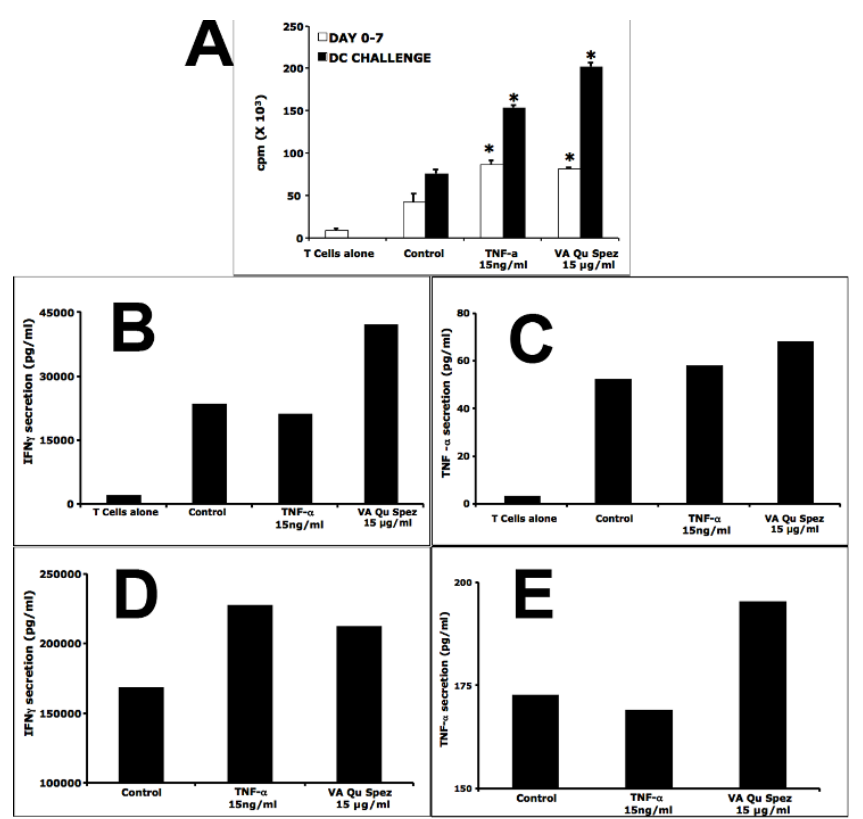

Figure 4

VA Qu Spez-treated DCs do not induce CD4+ T cell anergy. The 4-day-old DCs $\left(0.5 \times 10^{6}\right)$ were treated with medium alone (Control) or with $15 \mathrm{ng} / \mathrm{ml}$ TNF- $\alpha$ or with 15 $\mu \mathrm{g} / \mathrm{ml}$ of VA Qu Spez for 48 hours. The DCs were then cocultured with the allogeneic CD4+ $\mathrm{T}$ cells at $\mathrm{I}: \mathrm{I} 0$ ratio in a round bottom 96 -welled plate for 72 hrs for the first cycle of stimulation. The $T$ cells from in the co-cultures were then purified and were rested for $24 \mathrm{hrs}$ in the presence of $2 \mathrm{IU} /$ $\mathrm{ml}$ of IL-2. These CD4+ T cells were then subjected for second cycle of stimulation with similiarly treated DCs from same donor. After $48 \mathrm{hrs}$ of co-culture, the cells were pulsed overnight with $0.5 \mu \mathrm{Ci}(0.037 \mathrm{MBq})$ of $\left({ }^{3} \mathrm{H}\right)$ thymidine to quantify $\mathrm{T}$-cell proliferation (Panel A, filled bars). Radioactive incorporation was measured by standard liquid scintillation counting, and the results were expressed as counts per minute (mean \pm SEM of triplicate values). DC-T cell co-cultures of first cycle of stimulation that were maintained for 7 days were used for the comparison (Panel A, open bars). Statistical significance $(*, p<0.05)$ as analysed by Mann-Whitney test is indicated. The level of T cell cytokines IFN $\gamma$ (Panels B and D) and TNF- $\alpha$ (Panels $C$ and $E$ ) in the cell-free supernatants from above cultures were analysed by cytokine bead array. Panels B and C indicate the level of cytokines in DC-T cell co-cultures of first cycle of stimulation that were maintained for 7 days. Panels $D$ and $E$ present the level of cytokines in DC-T cell co-cultures of second cycle of stimulation.

and IL-1 $\beta$ for use in cancer immunotherapy [36]. Our data demonstrates that VA Qu Spez-mediated maturation of DCs and secretion of pro-inflammatory cytokines (IL-6 and IL-8) has repercussion on the stimulation of CD4+ T cells and their cytokine secretion. It is interesting to note that VA Qu Spez-treated DCs do not induce anergy of T cells as shown by the induction of proliferation and the

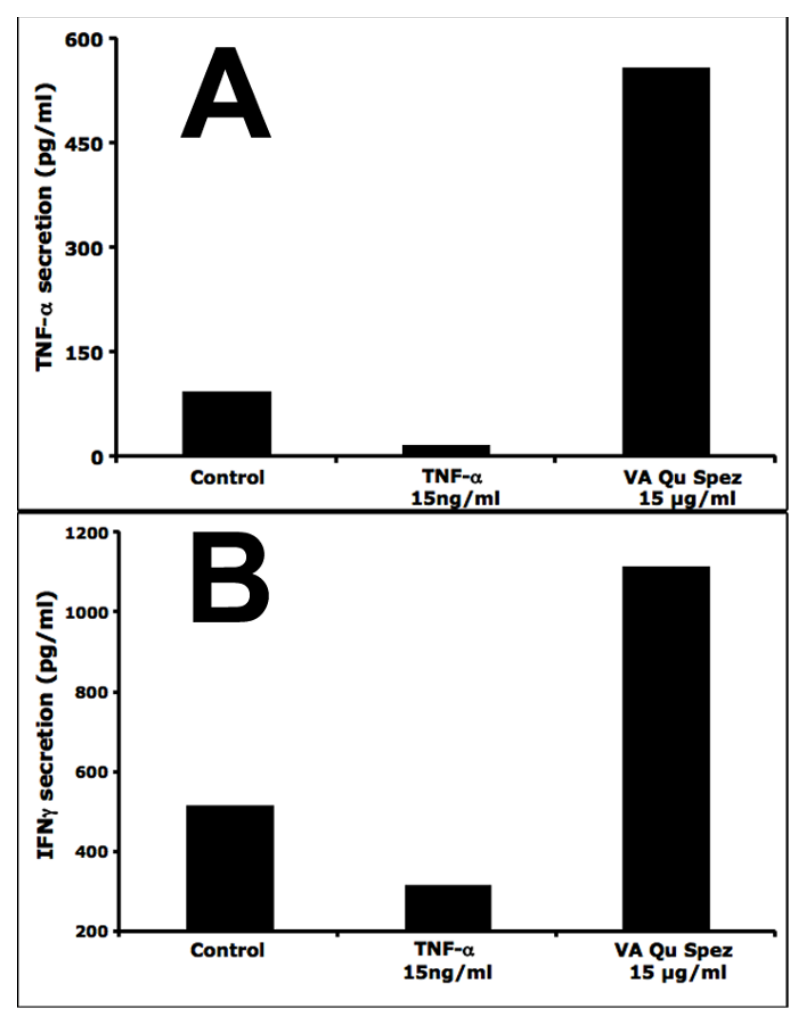

Figure 5

VA Qu Spez-treated DCs stimulate melanoma specific M77-80 CTL clone. The 4-day-old DCs $\left(0.5 \times 10^{6}\right)$ from HLA-A2 donor were treated with medium alone (Control) or with $15 \mathrm{ng} / \mathrm{ml}$ TNF- $\alpha$ or with $15 \mu \mathrm{g} / \mathrm{ml}$ of VA Qu Spez for 48 hours. The DCs ( $104 /$ well/200 $\mu$ l medium) were then cultured overnight with M77-80 CTLs $\left(10^{5}\right)$ in 96 well round-bottomed plates along with the MART-I peptide (I $\mu \mathrm{M})$ and $25 \mathrm{IU} / \mathrm{mL}$ rh IL-2. The activation of M77-80 was analyzed by measuring TNF $\alpha$ (Panel A) and IFN $\gamma$ (Panel B) in the cell free-supernatants by using cytokine bead array.

secretion of TNF- $\alpha$ and IFN $\gamma$ by the CD $4+$ T cells. Thus, induction of DC-cytokines and T cell cytokines by VA Qu Spez represents a critical determinant in the development of effective innate immune responses against the tumor cells [37].

CD8+ cytotoxic T lymphocytes (CTLs) are critical for the elimination of tumor. Thus, therapies aimed at expansion of CTLs and their functions holds the key in mounting an effective anti-tumor immune response. The ability of the CTLs to recognize the processed peptides derived from the cellular genes, such as those encoding MART-1 or tyrosinase in melanoma, led to the recognition that protective immune responses are often directed towards tumor-associated, rather than tumor-specific, antigens [28,29]. Using Melan-A/MART-1 specific M77-80 CTL clone, we have 
shown that DCs "educated" by VA Qu Spez can mount an anti-tumoral immune response as suggested by the increased levels of secretion of TNF- $\alpha$ and IFN $\gamma$ by the CTLs in the co-culture. Further studies on the effect of the VA preparations on the DCs that have been subjected to inactivation by tumor factors, may provide strategies in dissecting the stimulatory effects of the VA preparations on the DCs.

\section{Conclusion}

VA preparations are known to have cytotoxic properties towards the tumor cells. They are also known to improve the quality of life in the cancer patients. However, the mechanisms by which VA preparations stimulate the immune system and exert beneficial effects in patients are not yet clear. We have demonstrated the role of the VA preparations in stimulating the DCs with implications in the induction of anti-tumor immunity. However, these in vitro results need to be validated further in the context of clinical studies. The elucidation of immunostimulatory mechanisms of VA preparations is critical in understanding their role as complimentary therapy in cancer.

\section{Competing interests}

This work was supported by research grant from Weleda AG. The authors declare that they have no competing interests.

\section{Authors' contributions}

SE, SVK and JB participated in the study design. SE, JPDVH and SD performed experiments. SE, MDK, AF, SVK and JB analysed the data. SE, SVK and JB prepared the manuscript. All authors read and approved the final manuscript.

\section{Acknowledgements}

The authors thank Prof. Francine Jotereau and Dr. Nathalie Labarriere (INSERM U60I, Nantes, France) for the M77-80 CTL clone. The authors thank Rainier Dierdorf, Jean Chazarenc, Michael Werner and Marc Follmer for discussion. This work was supported by grants from Weleda AG, Switzerland, and by Institut National de la Santé et de la Recherche Médicale (INSERM) and Centre National de la Recherche Scientifique (CNRS), France. S.E is a recipient of fellowship from EGIDE, France.

\section{References}

I. Olsnes S, Stirpe F, Sandvig K, Pihl A: Isolation and characterization of viscumin, a toxic lectin from Viscum album L. (mistletoe). J Biol Chem 1982, 257(22): | 3263-13270.

2. Khwaja TA, Dias CB, Pentecost S: Recent studies on the anticancer activities of mistletoe (Viscum album) and its alkaloids. Oncology 1986, 43(Suppl I):42-50.

3. Franz $H$, Ziska $P$, Kindt $A$ : Isolation and properties of three lectins from mistletoe (Viscum album L.). Biochem J I98I, I 95(2):481-484.

4. Urech K, Schaller G, Jaggy C: Viscotoxins, mistletoe lectins and their isoforms in mistletoe (Viscum album L.) extracts Iscador. Arzneimittelforschung 2006, 56(6A):428-434.

5. Klopp R, Schmidt W, Werner E, Werner M, Niemer W, Beuth J: Influence of complementary Viscum album (Iscador) administration on microcirculation and immune system of ear, nose and throat carcinoma patients treated with radiation and chemotherapy. Anticancer Res 2005, 25(IB):60I-6I0.

6. Augustin M, Bock PR, Hanisch J, Karasmann M, Schneider B: Safety and efficacy of the long-term adjuvant treatment of primary intermediate- to high-risk malignant melanoma (UICC) AJCC stage II and III) with a standardized fermented European mistletoe (Viscum album L.) extract. Results from a multicenter, comparative, epidemiological cohort study in Germany and Switzerland. Arzneimittelforschung 2005, 55(I):38-49.

7. Braun JM, Ko HL, Schierholz JM, Beuth J: Standardized mistletoe extract augments immune response and down-regulates local and metastatic tumor growth in murine models. Anticancer Res 2002, 22(6C):4I87-4I90.

8. Park WB, Lyu SY, Kim JH, Choi SH, Chung HK, Ahn SH, Hong SY, Yoon TJ, Choi MJ: Inhibition of tumor growth and metastasis by Korean mistletoe lectin is associated with apoptosis and antiangiogenesis. Cancer Biother Radiopharm 200I, I 6(5):439-447.

9. Bussing A, Schietzel M: Apoptosis-inducing properties of Viscum album L. extracts from different host trees, correlate with their content of toxic mistletoe lectins. Anticancer Res 1999, I9( I A):23-28.

10. Stein GM, Pfuller U, Schietzel M, Bussing A: Toxic proteins from European mistletoe (Viscum album L.): increase of intracellular IL-4 but decrease of IFN-gamma in apoptotic cells. Anticancer Res 2000, 20(3A): 1673-1678.

II. Stein GM, Pfuller U, Schietzel M, Bussing A: Expression of interleukin-4 in apoptotic cells: stimulation of the type-2 cytokine by different toxins in human peripheral blood mononuclear and tumor cells. Cytometry 2000, 4 I (4):26I-270.

12. Stein GM, Pfuller U, Schietzel M, Bussing A: Intracellular expression of IL-4 and inhibition of IFN-gamma by extracts from European mistletoe is related to induction of apoptosis. Anticancer Res 2000, 20(5A):2987-2994.

13. Duong Van Huyen JP, Delignat S, Bayry J, Kazatchkine MD, Bruneval $P$, Nicoletti A, Kaveri SV: Interleukin- 12 is associated with the in vivo anti-tumor effect of mistletoe extracts in B 16 mouse melanoma. Cancer Lett 2006, 243(I):32-37.

14. Elluru S, Van Huyen JP, Delignat S, Prost F, Bayry J, Kazatchkine MD, Kaveri SV: Molecular mechanisms underlying the immunomodulatory effects of mistletoe (Viscum album L.) extracts Iscador. Arzneimittelforschung 2006, 56(6A):46I-466.

15. Drake CG, Jaffee E, Pardoll DM: Mechanisms of immune evasion by tumors. Adv Immunol 2006, 90:5I-8I.

16. Banchereau J, Steinman RM: Dendritic cells and the control of immunity. Nature 1998, 392(6673):245-252.

17. Banchereau J, Briere F, Caux C, Davoust J, Lebecque S, Liu YJ, Pulendran B, Palucka K: Immunobiology of dendritic cells. Annu Rev Immunol 2000, I 8:767-8II.

18. Cella M, Sallusto F, Lanzavecchia A: Origin, maturation and antigen presenting function of dendritic cells. Curr Opin Immunol 1997, 9(1): 10-16.

19. Steinman RM, Inaba K, Turley S, Pierre P, Mellman I: Antigen capture, processing, and presentation by dendritic cells: recent cell biological studies. Hum Immunol 1999, 60(7):562-567.

20. Inaba K, Turley S, Yamaide F, lyoda T, Mahnke K, Inaba M, Pack M, Subklewe M, Sauter B, Sheff D, et al:: Efficient presentation of phagocytosed cellular fragments on the major histocompatibility complex class II products of dendritic cells. J Exp Med 1998, I88(I I):2 I63-2173.

21. Rabinovich GA, Gabrilovich D, Sotomayor EM: Immunosuppressive strategies that are mediated by tumor cells. Annu Rev Immunol 2007, 25:267-296.

22. Wang Z, Cao Y, Albino AP, Zeff RA, Houghton A, Ferrone S: Lack of HLA class I antigen expression by melanoma cells SKMEL-33 caused by a reading frameshift in beta 2-microglobulin messenger RNA. J Clin Invest 1993, 9 I (2):684-692.

23. Natali PG, Nicotra MR, Bigotti A, Venturo I, Marcenaro L, Giacomini $P$, Russo C: Selective changes in expression of HLA class I polymorphic determinants in human solid tumors. Proc Natl Acad Sci USA 1989, 86(17):6719-6723.

24. Hicklin DJ, Marincola FM, Ferrone S: HLA class I antigen downregulation in human cancers: $\mathrm{T}$-cell immunotherapy revives an old story. Mol Med Today 1999, 5(4): I78-I86.

25. Rivoltini L, Carrabba M, Huber V, Castelli C, Novellino L, Dalerba P, Mortarini R, Arancia G, Anichini A, Fais S, et al.: Immunity to can- 
cer: attack and escape in $\mathbf{T}$ lymphocyte-tumor cell interaction. Immunol Rev 2002, 188:97-II3.

26. Parmiani G, Sensi M, Castelli C, Rivoltini L, Anichini A: T-cell response to unique and shared antigens and vaccination of cancer patients. Cancer Immun 2002, 2:6.

27. Steinbrink K, Wolfl M, Jonuleit H, Knop J, Enk AH: Induction of tolerance by IL-10-treated dendritic cells. J Immunol 1997, I 59(10):4772-4780.

28. Gervois N, Guilloux Y, Diez E, Jotereau F: Suboptimal activation of melanoma infiltrating lymphocytes (TIL) due to low avidity of TCR/MHC-tumor peptide interactions. J Exp Med 1996, I 83(5):2403-2407.

29. Guilloux Y, Lucas S, Brichard VG, Van Pel A, Viret C, De Plaen E, Brasseur $F$, Lethe $B$, Jotereau $F$, Boon $T$ : A peptide recognized by human cytolytic $T$ lymphocytes on HLA-A2 melanomas is encoded by an intron sequence of the $\mathbf{N}$-acetylglucosaminyltransferase $\mathbf{V}$ gene. J Exp Med 1996, I83(3): I I73-I I83.

30. Kichler-Lakomy C, Budinsky AC, Wolfram R, Hellan M, Wiltschke C, Brodowicz T, Viernstein H, Zielinski CC: Deficiences in phenotype expression and function of dentritic cells from patients with early breast cancer. Eur J Med Res 2006, I I (I):7-12.

31. Wolfram RM, Budinsky AC, Brodowicz T, Kubista M, Kostler WJ, Kichler-Lakomy C, Hellan M, Kahlhammer G, Wiltschke C, Zielinski $C C$ : Defective antigen presentation resulting from impaired expression of costimulatory molecules in breast cancer. Int $J$ Cancer 2000, 88(2):239-244.

32. Heinzerling L, von Baehr V, Liebenthal C, von Baehr R, Volk HD: Immunologic effector mechanisms of a standardized mistletoe extract on the function of human monocytes and lymphocytes in vitro, ex vivo, and in vivo. I Clin Immunol 2006, 26(4):347-359.

33. Stein GM, Bussing A, Schietzel M: Stimulation of the maturation of dendritic cells in vitro by a fermented mistletoe extract. Anticancer Res 2002, 22(6C):4215-4219.

34. Stein GM, Bussing A, Schietzel M: Activation of dendritic cells by an aqueous mistletoe extract and mistletoe lectin-3 in vitro. Anticancer Res 2002, 22(I A):267-274.

35. Hostanska K, Hajto T, Spagnoli GC, Fischer J, Lentzen H, Herrmann $R$ : A plant lectin derived from Viscum album induces cytokine gene expression and protein production in cultures of human peripheral blood mononuclear cells. Nat Immun 1995, I 4(5-6):295-304

36. Curti A, Isidori A, Ferri E, Terragna C, Neyroz P, Cellini C, Ratta M, Baccarani M, Lemoli RM: Generation of dendritic cells from positively selected CDI4+ monocytes for anti-tumor immunotherapy. Leuk Lymphoma 2004, 45(7): I419-1428.

37. Tsai JP, Chen HW, Cheng ML, Liu HK, Lee YP, Hsieh CL, Luh KT, Wu CW, Hsu LH, Chao TY, et al: Analysis of host versus tumor interaction in cancer patients: opposing role of transforming growth factor-betal and interleukin-6 in the development of in situ tumor immunity. Immunobiology 2005, 2 I 0(9):66 I-67I.

\section{Pre-publication history}

The pre-publication history for this paper can be accessed here:

http://www.biomedcentral.com/1471-2407/8/161/pre pub

\section{Publish with Bio Med Central and every scientist can read your work free of charge}

"BioMed Central will be the most significant development for disseminating the results of biomedical research in our lifetime. "

Sir Paul Nurse, Cancer Research UK

Your research papers will be:

- available free of charge to the entire biomedical community

- peer reviewed and published immediately upon acceptance

- cited in PubMed and archived on PubMed Central

- yours - you keep the copyright

Submit your manuscript here:

http://www.biomedcentral.com/info/publishing_adv.asp
BioMedcentral 